\title{
Limitations and challenges of laparoscopic surgery in a low-income country: example of the Gaston Berger Teaching Hospital of Saint-Louis (Senegal)
}

\section{Abdourahmane Ndong, ${ }^{a}, *$ Mohamed Lamine Diao, ${ }^{a}$ Jacques Noel Tendeng, ${ }^{a}$ Ousmane Thiam, ${ }^{a}$ Adja Coumba Diallo, ${ }^{a}$ Aliou Diouf, ${ }^{a}$ Diago Anta Dia, ${ }^{a}$ Saer Diop, ${ }^{a}$ Mactar Dieng, ${ }^{b}$ Moustapha Diedhiou, Philippe Manyacka Ma Nyemb, ${ }^{a}$ Mamadou Cisséa and Ibrahima Konatéa}

\author{
${ }^{a}$ Department of Surgery and ${ }^{b}$ Department of Anaesthesiology, Gaston Berger University, Saint-Louis, Senegal \\ ${ }^{*}$ Corresponding author at: Gaston Berger University, Road of Ngallelle, 234 Saint-Louis, Senegal. \\ Email: abdourahmane.ndong@ugb.edu.sn
}

Date accepted for publication: 16 February 2021

\section{Abstract}

Introduction: Despite the advances in minimally invasive surgery in developed countries, laparoscopy remains less used in low-resource settings. Our aim is to describe our first experience in laparoscopic surgery at the Saint-Louis Hospital (Senegal). Methods: This is a descriptive cross-sectional study over the period from November 1, 2018, to June 31, 2020. We included patients operated on by laparoscopy. The parameters studied were age, sex, indications, operative time, reasons, conversion rate, intraoperative difficulties, hospital stay, and postoperative complications. Results: We operated on 83 patients. The mean age was 33.3 years (range, 11-74 years). There were 37 men (44.5\%) and 46 women (55.5\%). The procedures included appendectomy (49.3\%), cholecystectomy (18.1\%), exploration of infertility (10.8\%), exploratory laparoscopy (7\%), and transabdominal preperitoneal (TAPP) for inguinal hernia repair (5.1\%). The conversion rate was $9.6 \%(n=8)$. The mean operative time was $81 \mathrm{~min}$ (range, 20-210 min). The average length of hospital stay was 2.7 days (range, $1-8$ days). The mortality rate was $2.4 \%(n=2)$. Conclusion: Laparoscopy has a real benefit even in a low-resource context. To develop minimally invasive surgery, emphasis must be placed on training the medical team and improving equipment.

Keywords: laparoscopy; surgery; low-income country; emergency; elective

\section{Introduction}

Despite the advances in minimally invasive surgery in developed countries, laparoscopy remains less used in lowresource settings. Some authors state that the laparoscopic approach may be inappropriate in low-middle income countries (LMIC), especially due to its cost. Its use also requires specialized training, technical support, and other urgent basic surgical needs. ${ }^{1}$

In Senegal, laparoscopic surgery was introduced in 1995 in the two main hospitals of the capital city, Dakar. ${ }^{2}$ From the beginning, the practice of laparoscopic surgery was almost exclusively carried out in these hospitals. In November 2018, laparoscopic surgery was started in Saint-Louis (Gaston Berger Teaching Hospital).

Senegal is a West African state and is considered to be a low-income country. Saint-Louis, the second largest city in the country, is located $260 \mathrm{~km}$ from Dakar, the capital.
Saint-Louis Regional Hospital is the referral hospital for the northern region of the country and has been affiliated to the Faculty of Health Sciences of Gaston Berger University of Saint-Louis since 2010.

The instrumental devices used for laparoscopic surgery are shown in Fig. 1 (screen, high-definition camera + LED light source, multi-function suction irrigation pump, $\mathrm{CO}_{2}$ insufflator, bipolar and unipolar energy source). Our aim in this study is to describe our first experience in laparoscopic surgery focusing on the main limitations and challenges.

\section{Methods}

We performed a descriptive cross-sectional study over the period from November 1, 2018, to June 31, 2020. We included patients operated by laparoscopy. The parameters studied were age, sex, indications, operative time, reasons, 


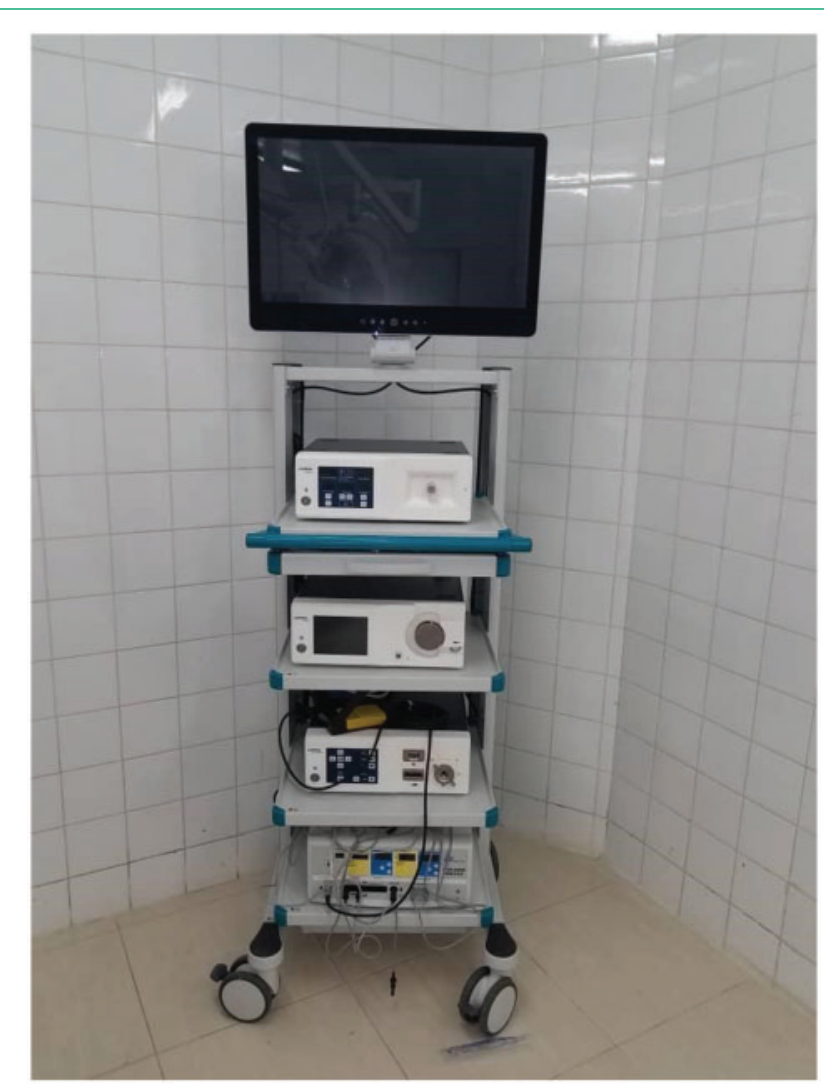

Figure 1. Laparoscopy unit (screen, high-definition camera + LED light source, multi-function suction irrigation pump, $\mathrm{CO}_{2}$ insufflator, bipolar and unipolar energy source.

conversion rate, intraoperative difficulties, hospital stay, and postoperative complications. The interventions were performed by the general surgery and gynaecology teams. The operators were senior surgeons who had training in laparoscopy assisted by surgical residents.

Data were retrieved prospectively from operative notes and patients' records. The data analysis was done with RStudio software version 1.1.447. Qualitative variables are presented as numbers and proportions; quantitative variables are presented as means with their range. A chi-squared test was used and a difference was considered significant when $P<$ 0.05 .

\section{Results}

We operated on 83 patients. The mean age was 33.3 years (range, 11-74 years). There were 37 men (44.5\%) and 46 women $(55.5 \%)$. The patient characteristics are shown in Table 1 .

It was an emergency intervention in $51.8 \%$ and scheduled in $48.2 \%$ of cases. The procedures performed were
Table 1. Characteristics of the study population ( $n=83$ )

\begin{tabular}{|c|c|c|c|}
\hline Characteristics & & Number & $\%$ \\
\hline \multirow[t]{2}{*}{ Gender } & Male & 37 & 44.5 \\
\hline & Female & 46 & 55.5 \\
\hline \multirow[t]{4}{*}{ Age range } & $11-20$ years & 11 & 13.1 \\
\hline & $20-40$ years & 48 & 57.7 \\
\hline & $40-60$ years & 20 & 24.1 \\
\hline & $\geqslant 60$ years & 4 & 5.1 \\
\hline \multirow{2}{*}{$\begin{array}{l}\text { American Society } \\
\text { of Anesthesiologists } \\
\text { class }\end{array}$} & I & 72 & 86.9 \\
\hline & II & 11 & 13.1 \\
\hline \multirow[t]{2}{*}{ Type of admission } & Scheduled & 40 & 48.2 \\
\hline & Emergency & 43 & 51.8 \\
\hline \multirow[t]{11}{*}{ Type of surgery } & Appendectomy & 41 & 49.3 \\
\hline & Cholecystectomy & 15 & 18.1 \\
\hline & Exploration of subfertility & 9 & 10.8 \\
\hline & Diagnostic laparoscopy & 6 & 7 \\
\hline & TAPP & 4 & 5.1 \\
\hline & Ovarian cystectomy & 3 & 3.8 \\
\hline & Hysterectomy & 1 & 1.2 \\
\hline & Adnexectomy & 1 & 1.2 \\
\hline & Suture of perforated ulcer & 1 & 1.2 \\
\hline & $\begin{array}{l}\text { Sigmoidectomy } \\
\text { coelio-assisted }\end{array}$ & 1 & 1.2 \\
\hline & Nissen fundoplication & 1 & 1.2 \\
\hline \multirow[t]{2}{*}{ Conversion rate } & Scheduled & 5 & 6 \\
\hline & Emergency & 3 & 3.6 \\
\hline \multirow[t]{3}{*}{$\begin{array}{l}\text { Reason for } \\
\text { conversion }\end{array}$} & $\begin{array}{l}\mathrm{CO}_{2} \text { leakage and } \\
\text { disruption }\end{array}$ & 2 & 2.4 \\
\hline & Adhesions & 5 & 6 \\
\hline & Bowel distension & 1 & 1.2 \\
\hline Complications rate & & 5 & 6 \\
\hline \multirow[t]{3}{*}{ Type of complication } & Surgical site infections & 2 & 2.4 \\
\hline & Biliary leakages & 2 & 2.4 \\
\hline & Caecal fistula & 1 & 1.2 \\
\hline Mortality & & 2 & 2.4 \\
\hline \multirow[t]{3}{*}{ Duration of surgery } & $<30 \min$ & 13 & 15.6 \\
\hline & $30-60 \mathrm{~min}$ & 16 & 19.2 \\
\hline & $>60 \min$ & 54 & 65.2 \\
\hline \multirow{3}{*}{$\begin{array}{l}\text { Length of } \\
\text { hospital stay }\end{array}$} & $<1$ day & 36 & 43.3 \\
\hline & 2-3 days & 27 & 32.5 \\
\hline & $>4$ days & 20 & 24.2 \\
\hline
\end{tabular}

appendectomy (49.3\%), cholecystectomy (18.1\%), exploration of subfertility (10.8\%), diagnostic laparoscopy (7\%), and transabdominal preperitoneal (TAPP) for inguinal hernia repair $(5.1 \%)$. 
The conversion rate was 9.6\% $(n=8)$. The reasons for conversion were technical in two cases $\left(\mathrm{CO}_{2}\right.$ leakage and disruption), adhesions in 5 cases and bowel distension in one case. Conversion was not associated with the mode of admission (scheduled or emergency) $(P=0.47)$.

The technical difficulties were poor calibration of the electrosurgical unit (4 cases), a defective trocar ( 2 cases), and a defective suction-irrigation unit (1 case).

The mean operative time was $81 \mathrm{~min}$ (range, $20-210 \mathrm{~min}$ ). The average length of hospital stay was 2.7 days (range, 1-8 days). There were five complications (6\%) (2 surgical site infections, 2 cases of biliary leakage, and 1 caecal fistula). There were two deaths (2.4\%) (pulmonary embolism and post-operative peritonitis).

\section{Discussion}

In our study, the most frequently performed surgical procedure was appendectomy in $49.3 \%$ of cases followed by cholecystectomy in $18 \%$. Since its introduction, the indications for laparoscopic surgery performed in our country have changed. Previous reports showed that the most frequent indications for laparoscopic surgery were duodenal ulcer for elective procedures, and appendicitis and its complications for emergency surgeries. ${ }^{5,6}$

Laparoscopic surgery has revolutionized surgical operations due to its unique advantages of a shorter hospital stay, minimal surgical trauma, and a better cosmetic outcome. But implementation in our context is not always easy; difficult constraints must be overcome. The first barrier is economic; health systems in underdeveloped countries are facing other urgent basic needs with regard to access to surgery. For example, it was estimated that in low-income countries, less than 1 operation takes place per 100,000 inhabitants. ${ }^{3}$ Adaptations by surgical teams in resource-limited contexts have shown that laparoscopy can be affordable and patient costs can be similar to those for laparotomy. ${ }^{4}$ Adaptive strategies combined with efforts to improve equipment can decrease costs and surmount other barriers to allow for more widespread utilization of laparoscopy in LMICs.

Performing laparoscopic surgery requires specialized knowledge and surgical teams. Hence, emphasis must be placed on training for surgeons and other members of the surgical team. ${ }^{4}$ Not only should laparoscopic skills be taught but also non-technical skills for surgeons with the aim of a quality improvement strategy. However, programmes for minimally invasive surgery training are not always available, therefore partnerships with international training programmes should be developed. This would allow the creation of home-based simulation centres with low-cost solutions.

A mortality rate of $2.4 \%$ is comparable with the results in a previous study in Dakar, which reported a mortality rate of $3.4 \%{ }^{7}$ Improving training and equipment could help to reduce these complications.

\section{Limitations}

The small size of the study population $(n=83)$ is the main limitation of our study. In addition, we were not able to compare the outcomes (mortality, complications) between laparoscopy and open surgeries performed in the same period. Further studies with adequate numbers of patients will be necessary.

\section{Conclusion}

Laparoscopic surgery is safe, effective, feasible, and costeffective in LMICs, although accessibility, acceptability, and quality often remain limited. It has a real benefit even in a low-resource context and should be encouraged. To develop minimally invasive surgery, emphasis must be placed on training the medical team and improving equipment.

\section{Conflict of interest}

The authors declare no conflict of interest.

\section{References}

1. Chao TE, Mandigo M, Opoku-Anane J, Maine R. Systematic review of laparoscopic surgery in low- and middle-income countries: benefits, challenges, and strategies. Surg Endosc 2016; 30: 1-10. https://doi.org/10.1007/s00464-015-4201-2.

2. Bendinelli C, Leal T, Moncade F, Dieng M, Toure CT, Miccoli P. Endoscopic surgery in Senegal. Surg Endosc Interv Tech 2002; 16: 1488-1492. https://doi.org/10.1007/s00464-0019188-1.

3. Stewart B, Khanduri P, McCord C, Ohene-Yeboah M, Uranues S, Vega Rivera F, et al. Global disease burden of conditions requiring emergency surgery. Br J Surg 2014; 101: e9-22. https://doi.org/10.1002/bjs.9329.

4. Choy I, Kitto S, Adu-Aryee N, Okrainec A. Barriers to the uptake of laparoscopic surgery in a lower-middle-income country. Surg Endosc 2013; 27: 4009-4015. https://doi. org/10.1007/s00464-013-3019-z.

5. Touré AO, Foba ML, Ka O, Cissé M, Dieng, MKa, I, et al. Laparoscopy in upper gastro-intestinal non tumoral pathologies: our experience in a low income country. Int J Surg Res 2015; 4: 11-14. https://doi.org/10.5923/j.surgery.20150402.01. 
6. Cissé ML, Touré AO, Tendeng JN, Seck M, Thiam M, Guèye $\mathrm{ML}$, et al. Apport de la laparoscopie devant les urgences abdominales au CHU A Le Dantec de Dakar, à propos de 144 cas. Le Journal de Coelio-chirurgie 2015; 95: 1-4.
7. Niasse A, Faye PM, Ndong A, Toure AO, Thiam O, Gueye ML, et al. Morbidity of laparoscopy surgery at the General Surgery Department of Aristide Le Dantec Hospital: retrospective study of 43 cases. J Surg Res Ther 2020; 3: 5-9. 